\title{
The volume and pressure overloads of the heart
}

\author{
Las sobrecargas de presión y de volumen del corazón \\ Daniel Manzur-Sandoval', Luis A. Baeza Herrera², Eric N. Cuevas-Medina² y José A. Cornejo-Guerra ${ }^{3 *}$ \\ ${ }^{1}$ Unidad de Terapia Intensiva Cardiovascular; ${ }^{2}$ Departamento de Cardiología; ${ }^{3}$ Departamento de Cardiología Intervencionista. Instituto Nacional de \\ Cardiología Dr. Ignacio Chávez, Ciudad de México, México
}

\section{Dear Editor:}

The contribution of the Mexican School of Electrocardiography is based mainly on its deductive nature. Its main contributions include the description of the normal ventricular activation, the study of intraventricular conduction disorders ${ }^{1-2}$, description of the electrophysiological phenomena in acute acute myocardial infarction $^{3}$ and the effect of the pressure and volume overloads in the heart. The first electrocardiographic description of volume overload in our institution was done by Dr. Cabrera when he observed changes in repolarization in V5-V6 in a patient with a peripheral arteriovenous fistula when he intermittent occluded and recorded $i^{4-5}$. We discuss the ECG of a patient with mitral regurgitation as an example of the left ventricle's volume overload and resolution of the abnormalities after surgical correction. Later, we conducted a review of the electrophysiopathological processes involved in the hemodynamic overloads with ECG as examples.

\section{Case report}

A 46-year-old male with 1-month dyspnea of exertion and non-productive cough; 3 weeks later, the dyspnea increased until presenting orthopnea. He was admitted to our institution with HR $112 \mathrm{bpm}, \mathrm{RR} 18 \mathrm{pm}$, BP
$114 / 81 \mathrm{~mm} \mathrm{Hg}$, temperature $36.5^{\circ} \mathrm{C}$, and SatO2 of $92 \%$. The physical findings revealed a regurgitant systolic murmur in the left sternal border, with irradiation to the axilla. ECG showed tall pointed and symmetrical $T$ waves in V5-V6 (Fig. 1a). Chest X-ray revealed dilation of the left cavities with pulmonary venocapillary hypertension. Transthoracic echocardiogram (TTE) showed severe mitral regurgitation (due to flail of the P2 segment of the posterior leaflet) with dilation of the left atrium and left ventricle and left ventricular end-diastolic volume of $140 \mathrm{ml} / \mathrm{m}^{2}$. The patient underwent mitral valve repair and annuloplasty with a prosthetic ring with adequate post-operative evolution; post-surgical electrocardiogram revealed resolution of the repolarization abnormalities (Fig. 1b), with an important reduction of the telediastolic volume of the left ventricle $101.8 \mathrm{~mL} / \mathrm{m}^{2}$ determined by TTE.

\section{Discussion}

Abnormalities in T wave have been defined as "primary" when they are the consequence of alterations in repolarization, such as in myocardial ischemia or electrolyte imbalances or "secondary" when they are the result of alterations in the intraventricularconduction process, such as in branch blockages or hypertrophies ${ }^{6}$.

\section{Correspondence:}

José A. Cornejo-Guerra

Cardiología Intervencionista

Instituto Nacional de Cardiología "Dr. Ignacio Chávez"

Ciudad de México, México

Date of reception: 08-11-2019

Date of acceptance: 10-01-2020

E-mail: jacornejoguerra @gmail.com

DOI: $10.24875 /$ ACM.20000366
Available online: 00-00-2020 Arch Cardiol Mex (Eng). 2020;90(2):246-248 www.archivoscardiologia.com 1405-9940/○ 2020 Instituto Nacional de Cardiología Ignacio Chávez. Publicado por Permanyer. Este es un artículo open access bajo la licencia CC BY-NC-ND (http://creativecommons.org/licenses/by-nc-nd/4.0/) 
In his landmark paper, Dr. Enrique Cabrera (at the Electrocardiography Department of Instituto Nacional de Cardiología) established the following principles regarding the effect of pressure and volume overload on the electrocardiogram: (1) Starling mechanism is the main determinant of volume overloads, (2) each type of hemodynamic overload has its electrocardiographic representation, (3) right bundle branch block (RBBB) appears in the right ventricle's (RV) volume overload, (4) there are tall $R$ waves and secondary $T$ waves in V1-V2 in the RVs pressure overload, and (5) there are primary T waves (tall, pointed, and symmetrical) in V5V6 in the left ventricle's volume overload ${ }^{5,6}$.

\section{Left ventricular pressure overload}

This electrocardiographic manifestation occurs in entities with increased systolic wall stress of the left ventricle (aortic stenosis, systemic arterial hypertension, hypertrophic cardiomyopathy). There are a ST-segment and asymmetric negative T wave in V5-V6 (Fig. 2a). This phenomenon is consequence of the greater wall thickness of the left ventricle wall, which delays the activation of the muscle near the epicardium and consequently repolarization, so the repolarization vector points from epicardium to endocardium, away from V5V6; conditioning T-axis deviation opposite to the QRS axis?.

\section{Left ventricular volume overload}

This electrocardiographic changes occur in entities with increased diastolic wall stress of the left ventricle (Aortic regurgitation, mitral regurgitation, and ventricular septal defect). Its electrocardiographic expression is the presence of tall, pointed, and symmetric $T$ waves in V5-V6 (Fig. 2b) ${ }^{5}$. There could be concave ST-segment elevation. It has been suggested that these findings may be a consequence of increased end-diastolic volume, end-diastolic pressure, and the consequent decrease in subendocardial coronary perfusion in diastole.

\section{Right ventricular pressure overload}

A similar phenomenon takes place in the RV when there is pressure overload. In this case, there are tall $R$ waves with ST-segment depression and secondary asymmetric $\mathrm{T}$ waves in V1-V2, in addition to T-axis left deviation, opposite to the QRS axis ${ }^{5}$. This phenomenon can be observed in patients with pulmonary

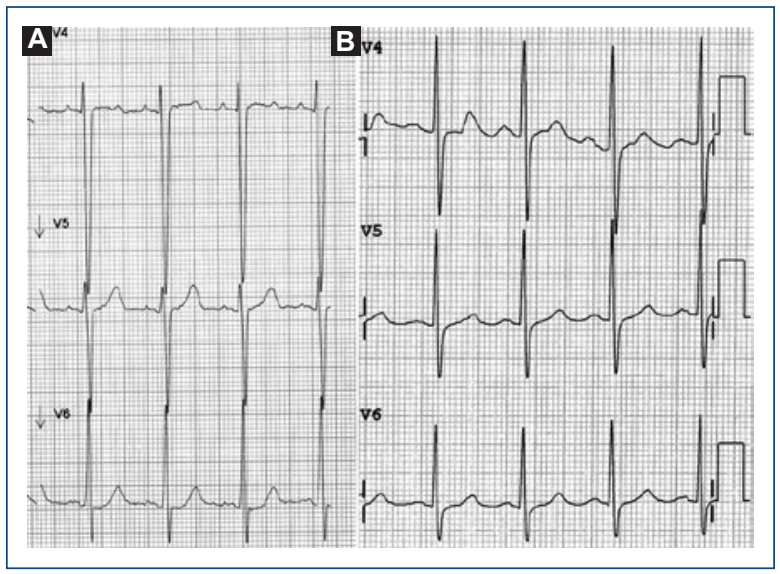

Figure 1. A: V4-V6 leads of the ECG at hospital admission. The left precordial leads show rectification of the ST segment and positive $T$ waves, suggestive of diastolic (volume) overload of the left ventricle. B: V4-V6 leads of the ECG at surgical intensive care unit. Note the disappearance of the alterations suggestive left ventricle overload.

hypertension of different etiologies or in congenital heart diseases (Fig. 2C).

\section{Right ventricular volume overload}

Given the greater compliance and capacitance of the $\mathrm{RV}$, entities with volume overload (atrial septal defect and tricuspid regurgitation) present the right RBBB instead of $\mathrm{T}$ wave abnormalities since RV tolerates great volume overloading without increasing its end-diastolic pressure (Fig. 2d) ${ }^{8}$.

\section{Conclusions}

The ECG is a low cost, accessible, and non-invasive tool. However, during the past decades, its interpretation has been limited to the recognition of electrocardiographic patterns. The Mexican School of Electrocardiography, established accurate diagnoses through deductive analysis. This method should be the one that predominates in the evaluation of the patient with suspected heart disease.

\section{Acknowledgments}

To the Mexican School of Electrocardiography.

\section{Funding}

None. 


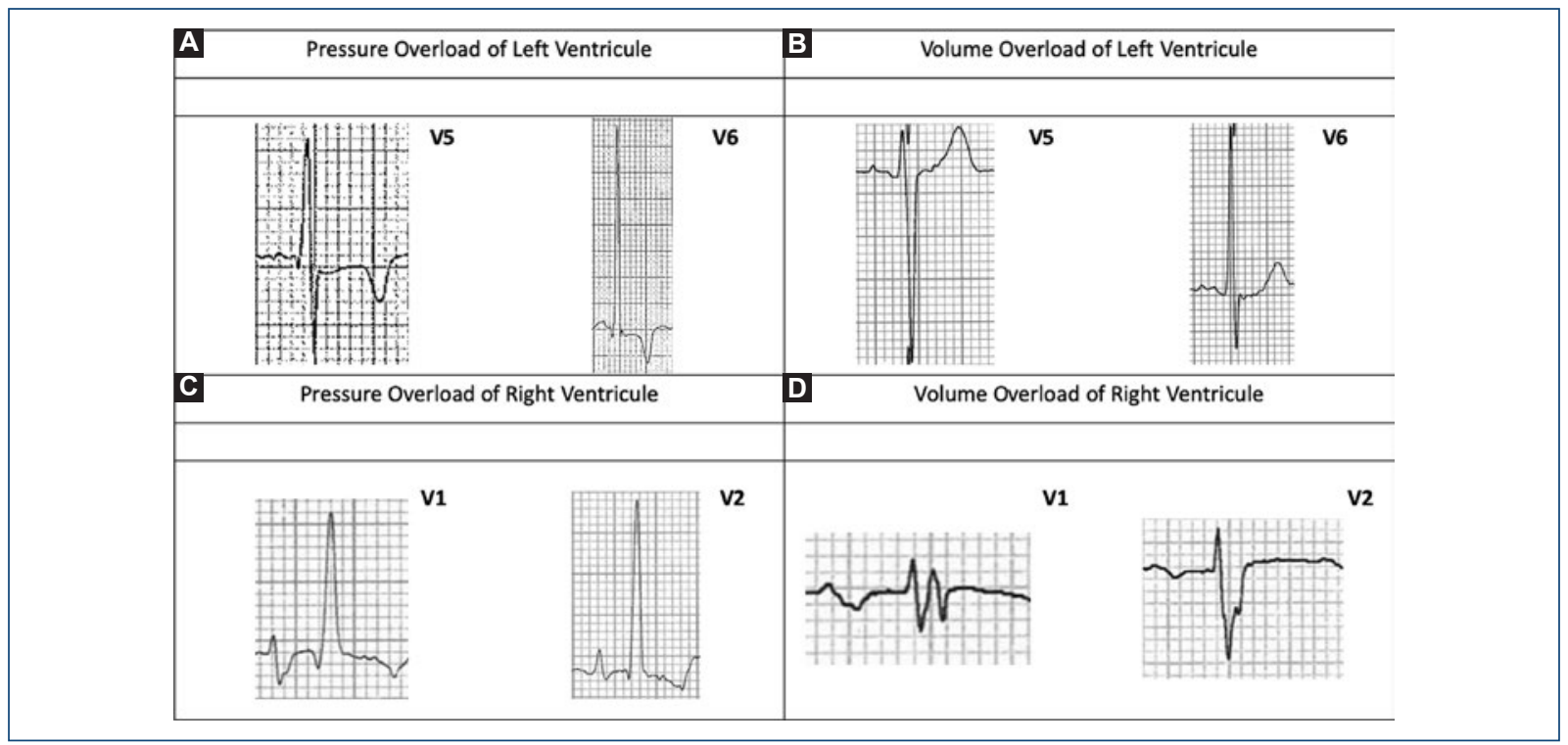

Figure 2. Examples of pressure and volume overload. A: Female, 58 years old, with aortic stenosis. TTE shows aortic valve area of $0.5 \mathrm{~cm}^{2}$, maximum velocity $4.3 \mathrm{~m} / \mathrm{s}$, and mean gradient $44 \mathrm{mmHg}$. B: Male, 46 years old, with severe mitral regurgitation due to flail of P2 segment of posterior valve. C: Male, 21 years old, with Fallot tetralogy who went surgery in 2005 for complete reparation of congenital defect and placement of a biologic valve in pulmonary position. In the follow-up, this patient develops infundibular stenosis and prosthetics stenosis. Pulmonary valve mean gradient $67 \mathrm{mmHg}$, pulmonary valve area $1.5 \mathrm{~cm}^{2}$. D: Male, 58 years old, with ostium primum atrial septal defect. The defect size is $7 \mathrm{~mm}$, $\mathrm{QP} / \mathrm{QS}$ 2:1, moderate tricuspid regurgitation and systolic pulmonary pressure of $50 \mathrm{mmHg}$.

\section{Conflicts of interest}

None declared.

\section{Ethical disclosures}

Protection of human and animal subjects. The authors declare that no experiments were performed on humans or animals for this study.

Confidentiality of data. The authors declare that they have followed the protocols of their work center on the publication of patient data.

Right to privacy and informed consent. The authors declare that no patient data appear in this article.

\section{References}

1. Medrano GA, De Micheli A, Cisneros F, Sodi-Pallares D. The anterior subdivision block of the left bundle branch of His. I. The ventricular activation process. J Electrocardiol. 1970;3:7-11.

2. Medrano GA, Brenes CP, De Micheli A, Sodi-Pallares D. Block of the posterior subdivision of the left bundle branch of His. J Electrocardiol. 1970;3:309-15.

3. Medrano G, Aranda A, Meléndez G, de Micheli A. On the actual nomenclature of myocardial infarcts. Arch Cardiol Méx. 2010;80:126-32.

4. Enrique C, Monroy J. Systolic and diastolic loading of the heart. I. Am Heart J. 1952;43:661-8.

5. Enrique C, Monroy J. Systolic and diastolic loading of the heart. II. Am Heart J. 1952;43:669-86.

6. Rosen MR. Why T waves change: a reminiscence and essay. Heart Rhythm. 2009;6:S56-61.

7. de Micheli A, Medrano GA, Aranda A. Electrical features of hypertrophied left heart. Arch Cardiol Mex. 2003;73:135-42.

8. Milnor W, Bertrand C. The electrocardiogram in atrial septal defect. Am J Med. 1957;22:223-33. 